EXTENDED REPORT

\title{
Surgical induction of chorioretinal venous anastomosis in ischaemic central retinal vein occlusion: a non-randomised controlled clinical trial
}

\author{
A Mirshahi, R Roohipoor, A Lashay, S F Mohammadi, M R Mansouri
}

Br J Ophthalmol 2005;89:64-69. doi: 10.1136/bjo.2004.045278

See end of article for authors' affiliations .......................

Correspondence to: Dr S F Mohammadi, Eye Research Center, Farabi Eye Hospital, Tehran University of Medical Sciences, PO Box 14155-7146, Tehran Iran; sfmohamm@ razi.tums.ac.ir

Accepted for publication 2 May 2004
Aim: To evaluate the safety and efficacy of surgical induction of chorioretinal venous anastomosis in the management of ischaemic central retinal vein occlusion (CRVO).

Methods: In a comparative clinical trial, 28 patients with ischaemic CRVO were included, of whom 18 who declined surgery were considered as controls. The 10 surgical cases underwent standard vitrectomy with incisions into the choroids adjacent to the partially cut major retinal veins. Mersilene suture insertion was done to induce chorioretinal venous shunt. Mild endolaser was applied. Patients were followed up for 6-18 (mean 10) months.

Results: Clinical success in shunt development was $90 \%$. Surgical cases had a significantly better visual acuity improvement compared with controls (mean difference: 1.5 logMAR, $p=0.001$ ) with $80 \%$ of them showing improvement (compared with $28 \%$ of the controls, $p=0.016$ ). Neovascularisation developed in $39 \%$ of the control group compared with $0 \%$ of the surgical cases $(p=0.03)$. In multivariate analysis, surgery remained the sole significant predictor of visual improvement. There were three re-operations for vitreous cavity haemorrhage, cataract, and retinal detachment.

Conclusions: Surgical induction of chorioretinal venous anastomosis may result in visual acuity improvement and prevent neovascularisation in ischaemic CRVO. Randomised studies are needed to compare the current study modality with the natural course of CRVO and emerging procedures, such as optic neurotomy, in the management of ischaemic CRVO.
C entral retinal vein occlusion (CRVO) is a relatively common cause of visual loss; after diabetic retinopathy, it is the most frequent vascular accident. ${ }^{1}$ The prevalence and five year incidence of CRVO were estimated to be $0.1-0.4 \%$ and $0.2 \%$, respectively. ${ }^{23}$ The two most frequent complications of $\mathrm{CRVO}$ are persistent macular oedema and neovascular glaucoma.

There are two types of CRVO-ischaemic and nonischaemic. Almost $20 \%$ of the cases are of ischaemic type at presentation, with some $10 \%$ of the non-ischaemics eventually converting to ischaemic type. ${ }^{4}$ In the non-ischaemic category, $48 \%$ of the patients go on to complete resolution and anterior segment neovascularisation is rare. But in the ischaemic group visual outcome is poor and only $10 \%$ of patients gain a visual acuity (VA) better than 20/400, and there is a high incidence of iris neovascularisation (up to $60 \%)^{5}$

Several reports have suggested restoring the venous outflow by: (1) creating a laser or surgically induced chorioretinal anastomosis; (2) administering recombinant tissue plasminogen activators; (3) cannulating the retinal vein transvitreally; (4) transecting the posterior scleral ring, and (5) radial optic neurotomy. ${ }^{6}{ }^{7}$ These modalities are largely advocated for the non-ischaemic subtype and limited studies have been done so far on the ischaemic types.

A variety of procedures have been proposed for the iatrogenic induction of chorioretinal venous anastomosis in non-ischaemic types, including diathermy (Verhoeff, 1948) and Argon laser photocoagulation (McAllister et al, 1995). ${ }^{9}$ Vitrectomy combined with intentional interruption of retinal vein in a group of intermediate CRVO cases also reported by Koizumi et al in 2002. ${ }^{10}$

In 1999, Fekrat et al performed venipuncture to induce the venous shunt in a case of ischaemic CRVO. ${ }^{11}$ In the same year, Peyman et al reported surgical chorioretinal venous anastomosis for the ischaemic subtype in which, following standard vitrectomy, they inserted Mersilene suture beneath the retina, adjacent to the major retinal veins. ${ }^{12}$ The surgical approach was modified by Quiroz-Mercado et al in 2001 in which, following vitrectomy, they applied Erbium:YAG laser to induce shunt formation. ${ }^{13}$ All groups reported their findings in a non-comparative fashion and concluded that the procedures might improve prognosis in some of the eyes affected with ischaemic CRVO.

The purpose of the current study is to evaluate the success of the surgical induction of venous chorioretinal shunt formation and its efficacy in terms of visual improvement and prevention of neovascularisation in a comparative trial.

\section{MATERIAL AND METHODS Setting}

This is a non-randomised controlled trial on patients with ischaemic CRVO referred to Farabi Eye Hospital. The study was approved by the Hospital Review Committee. The criteria for diagnosis were: a VA of less than 20/200, the presence of a relative afferent pupillary defect of $2+$ or more, extensive retinal haemorrhage and 10 or more disc areas of capillary non-perfusion (fig 1), and the absence of neovascularisation. Twenty eight of the 32 referred cases in the period of March 2001 to October 2003 were included. The risks and benefits of the surgical modality were fully explained to all patients and written informed consent was obtained. The patients who declined the surgery were considered as the controls.

Abbreviations: CRVO, central retinal vein occlusion; VA, visual acuity 


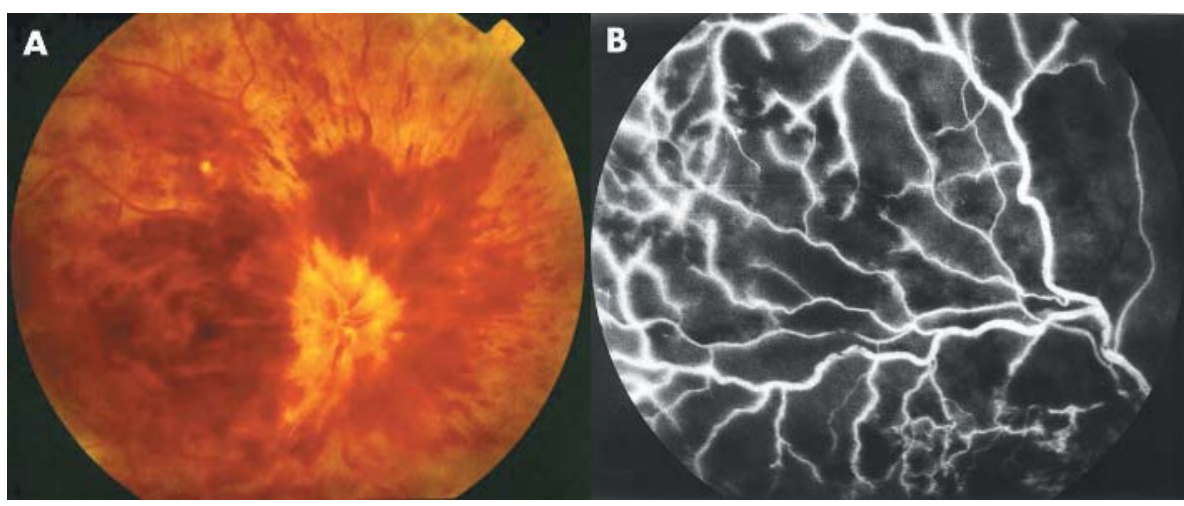

Figure 1 Baseline fundus photograph (A) of case number 4 and fluorescein angiography (B) of case number 10 ,

showing extensive retinal haemorrhage and capillary non-perfusion

characteristic of ischaemic central retinal vein occlusion.

\section{Examinations and the procedure}

The baseline VA, relative afferent pupillary defects, slit lamp exam, intraocular pressure, funduscopic, and gonioscopic findings were recorded. Fundus photography and fluorescein angiography were also performed. Following surgery, patients were examined weekly in the first month, monthly for six months, and every other month thereafter. Fundus photographs and retinal fluorescein angiography were repeated at months 1 and 3 and at the last follow up to evaluate shunt development and patency.

The surgical procedure was a standard three port vitrectomy followed by creation of posterior hyaloid separation and removal of the posterior cortical vitreous; then slit-like incisions were made with a microvitreoretinal blade through Bruch's membrane, adjacent to the major branch of retinal vein in each quadrant (a total of 1-4 shunts were attempted). After that, the subjacent vein was partially cut off and small pieces of 5-0 Mersilene suture were inserted in the incised sites (to maintain its patency and to promote formation of collateral channels) (fig 2). Endolaser treatment was applied around the incision sites followed by mild peripheral retinal photocoagulation. The parameters were: a power of 200$500 \mathrm{~mW}$ and duration of $200 \mathrm{~ms}$ for $300-800$ spots.

\section{Shunt patency evaluation}

A combination of fundus photographic and angiographic criteria were applied to evaluate the functionality of the shunts. ${ }^{1014}$ Criteria to evaluate shunt function; fundus photographic and fluorescein angiographic clues:

1. Thinning of the venous segment proximal to the anastomosis (fig 2) or asymmetric vein diameter at the disc.

2. Reverse tapering sign (increasing venous diameter further from disc).

3. Trilaminar flow.

4. Retrograde venous flow between the disc and the anastomosis.

5. Sharp change in hyperfluorescence at the anastomosis (this sign suggests a relative discontinuation in the thickness of fluorescein column at an anastomosis site).

6. Disappearance of the vein at the anastomosis (fig 2).

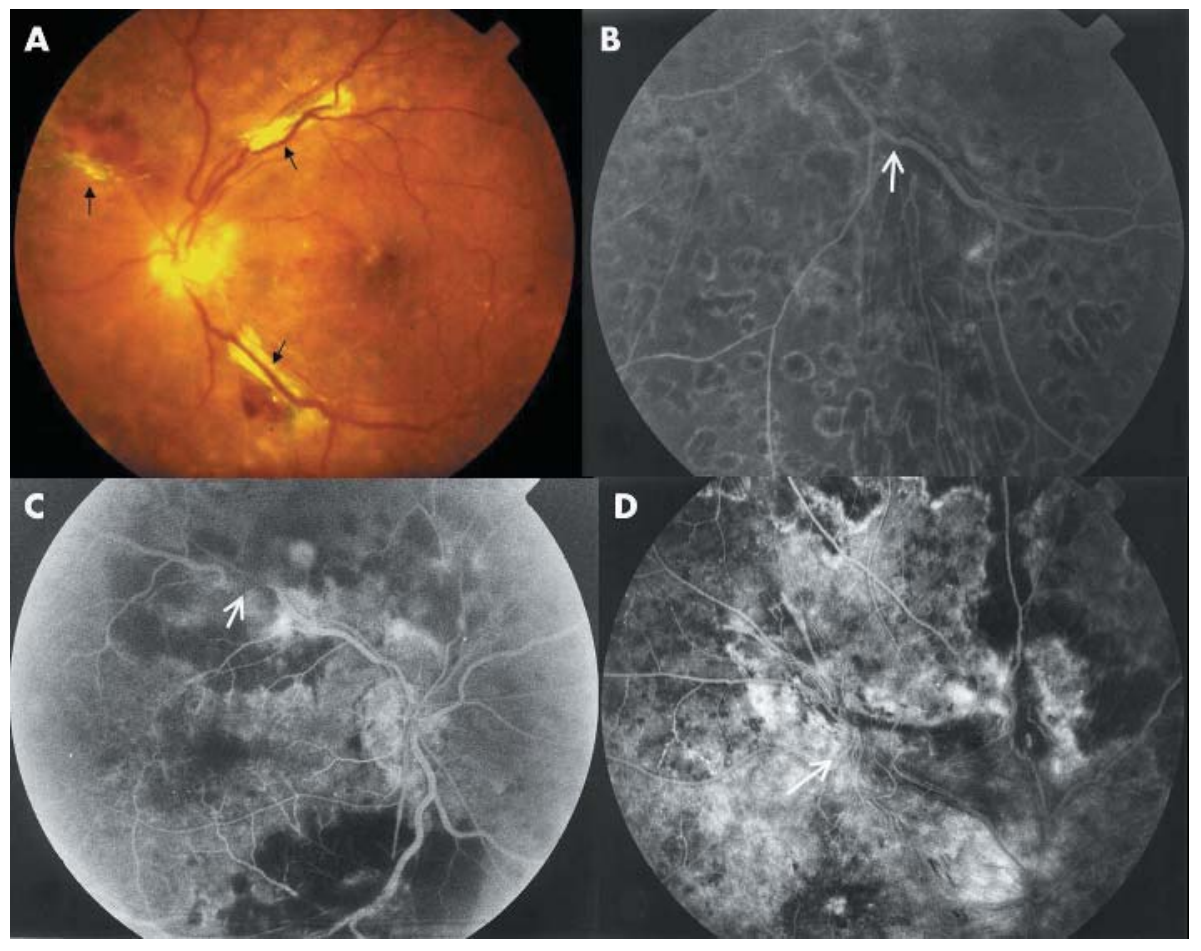

Figure 2 (A) Case number 1: eight week post-surgical fundus photograph depicting three attempted shunts (retinal haemorrhage and oedema have resolved). (B) Case number 5: thinning of the venous segment proximal to the anastomosis site. (C) Case number 3 : disappearance of the vein at the anastomosis sites. (D) Case number 4 development of collaterals without leakage at the attempted shunt site. 


\section{Analysis}

By "presentation time" we mean the time period from the onset of vein occlusion to the time of referral and the expression "month 8 post-event VA" refers to the visual acuity eight months after the occurrence of vein occlusion. The VA data were converted into logMAR equivalents ${ }^{15}$ and all the statistical analyses of VA were based on this notation. The Mann-Whitney $U$ and the Wilcoxan ranked tests were used to compare the VA data of the two study groups and to compare baseline with month 8 post-event VA of the surgical cases respectively. The $\chi^{2}$ test was used to compare VA improvement between early and late presentation times in the surgical cases, to compare VA improvement between the two groups, and to compare the occurrence of neovascularisation.

To evaluate the effect of (potential) confounders, the two groups were compared for age, sex, ocular and systemic associations, presentation time, and presentation VA with $\chi^{2}$ and Mann-Whitney U tests. Multinomial logistic regression analysis was used to evaluate the association of the three outcomes of month 8 post-event VA, VA improvement, and neovascularisation with three baseline covariates of presentation time, presentation VA, and the study group.

\section{RESULTS}

Of the 32 referred patients, 28 met the inclusion criteria. Ten of the participants consented to surgery. The age range was 33-80 years (mean 60 (SD 13) years). Fifteen cases were male. The range of presentation time was $1-6$ months (mean 2 (SD 1.5) months). Median VA at presentation was counting fingers at $1.5 \mathrm{~m}$ equivalent to 20/800 (range: HM to 20/240). For details of the cases see table 1 .
All of the surgical patients developed at least one active shunt and the surgical success rate (patent/attempted) was $47 \%$ (as stated in the methods section, $1-4$ shunts were made for every eye) (see fig 2). The course of case number 9 was complicated by retinal detachment, so we calculated our clinical success (defined as uneventful postoperative course and developing at least one active, inferiorly placed shunt) as $90 \%(9 / 10)$.

The patients were followed for 6-18 months (mean 10 months). Three patients needed further operations for cataract, vitreous cavity haemorrhage, and retinal detachment (as stated)—cases number 4, 10, and 9, respectively (see table 1). No other significant complications occurred. Collaterals at the shunt site (without leakage) were observed in two of the patients (fig 2).

The visual acuity improvement (month 8 post-event VA minus presentation VA) was $1.5 \log$ MAR units more in the surgical group $(\mathrm{p}=0.001$; actually control subjects lost 0.57 $\log$ MAR and the surgical patients achieved $0.94 \log M A R$ units). The means of $\log$ MAR month 8 post-event VA were equivalent to counting fingers at $2 \mathrm{~m}$ and $0.5 \mathrm{~m}$ for the surgical and control cases, respectively. When presentation VA was compared with the month 8 post-event VA, in a paired fashion for the surgical group, again the improvement in VA $(0.94 \log$ MAR units) was significant $(\mathrm{p}=0.044)$. Overall, $80 \%$ of the surgical cases showed visual acuity improvement compared with $28 \%$ of the controls $(p=0.016)$. In the surgical group, those with presentation times less than 3 months had 1 logMAR unit more improvement in their vision $(\mathrm{p}=0.134)$.

Seven of the controls (39\%) developed neovascularisation compared with none in the surgical group $(p=0.03)$. Four

Table 1 Clinical and demographic characteristics of the participants

\begin{tabular}{|c|c|c|c|c|c|c|c|c|c|}
\hline No & Age & Sex & Eye & Associations & $\begin{array}{l}\text { Presentation } \\
\text { time (months) }\end{array}$ & Baseline VA & $\begin{array}{l}\text { Month } 8 \text { post- } \\
\text { event VA }\end{array}$ & Neovascularisation & $\begin{array}{l}\text { Shunts patent/ } \\
\text { attempted }\end{array}$ \\
\hline \multicolumn{10}{|c|}{ Surgical group } \\
\hline 1 & 76 & $\mathrm{~F}$ & $\mathrm{~L}$ & $\mathrm{HTN}, \mathrm{HCH}$ & 4 & $\mathrm{HM}$ & $20 / 400$ & - & $1 / 4$ \\
\hline 2 & 65 & $M$ & $\mathrm{R}$ & $\mathrm{HCH}$ & 6 & $20 / 600$ & $20 / 200$ & - & $2 / 4$ \\
\hline 3 & 76 & $\mathrm{~F}$ & $\mathrm{R}$ & $\begin{array}{l}\mathrm{HTN}, \mathrm{HCH} \text {, } \\
\text { glaucoma }\end{array}$ & 4 & $20 / 6000$ & $20 / 6000$ & - & $2 / 3$ \\
\hline 4 & 34 & M & L & - & 3 & $20 / 1200$ & $20 / 200$ & - & $\begin{array}{l}2 / 3 \text {, complicated by } \\
\text { cataract }\end{array}$ \\
\hline 5 & 67 & $\mathrm{~F}$ & $\mathrm{R}$ & $\begin{array}{l}\mathrm{DM}, \mathrm{HCH} \text {, } \\
\text { glaucoma }\end{array}$ & 5 & $\mathrm{HM}$ & $20 / 1200$ & - & $2 / 3$ \\
\hline 6 & 70 & $\mathrm{~F}$ & $\mathrm{R}$ & - & 3 & $20 / 12000$ & $20 / 1600$ & - & $1 / 4$ \\
\hline 7 & 65 & $\mathrm{~F}$ & $\mathrm{~L}$ & HTN & 2 & $20 / 4000$ & $20 / 50$ & - & $2 / 4$ \\
\hline 8 & 33 & $M$ & $\mathrm{~L}$ & - & 2 & $20 / 1200$ & $20 / 100$ & - & $1 / 2$ \\
\hline 9 & 65 & $\mathrm{~F}$ & $\mathrm{R}$ & $\mathrm{HTN}, \mathrm{HCH}$ & 4 & $20 / 1200$ & $\mathrm{HM}$ & - & $1 / 3$, complicated by RD \\
\hline 10 & 70 & $M$ & $\mathrm{R}$ & $\mathrm{HTN}, \mathrm{HCH}$ & 3 & $H M$ & $20 / 400$ & - & $\begin{array}{l}1 / 3 \text {, complicated by } \\
\text { vitreous cavity } \\
\text { haemorrhage }\end{array}$ \\
\hline \multicolumn{10}{|c|}{ Control group } \\
\hline 11 & 40 & $M$ & $\mathrm{~L}$ & - & 1 & $20 / 320$ & $20 / 50$ & - & - \\
\hline 12 & 50 & $\mathrm{~F}$ & $\mathrm{R}$ & HTN & 1 & $20 / 1200$ & $\mathrm{HM}$ & - & - \\
\hline 13 & 70 & $\mathrm{~F}$ & $\mathrm{R}$ & $\mathrm{HTN}$ & 3 & $20 / 600$ & $\mathrm{HM}$ & + & - \\
\hline 14 & 79 & $M$ & $\mathrm{~L}$ & Glaucoma & 1 & $20 / 2400$ & $\mathrm{HM}$ & + & - \\
\hline 15 & 65 & $M$ & $\mathrm{~L}$ & - & 1 & $20 / 500$ & $20 / 320$ & - & - \\
\hline 16 & 51 & $M$ & $\mathrm{R}$ & - & 1 & $20 / 320$ & $\mathrm{HM}$ & + & - \\
\hline 17 & 65 & $\mathrm{~F}$ & $\mathrm{~L}$ & Glaucoma & 2 & $20 / 600$ & $20 / 4000$ & - & - \\
\hline 18 & 69 & $M$ & L & $\mathrm{HCH}$ & 1 & $20 / 1200$ & $20 / 400$ & - & - \\
\hline 19 & 53 & $\mathrm{~F}$ & $\mathrm{R}$ & $\mathrm{HTN}$ & 1 & $20 / 400$ & $20 / 30$ & - & - \\
\hline 20 & 60 & $\mathrm{~F}$ & $\mathrm{R}$ & HTN & 1 & $20 / 600$ & $\mathrm{HM}$ & + & - \\
\hline 21 & 51 & $M$ & $\mathrm{R}$ & HTN, glaucoma & 1 & $20 / 400$ & $\mathrm{HM}$ & + & - \\
\hline 22 & 59 & $\mathrm{~F}$ & $\mathrm{~L}$ & HTN & 1 & $20 / 600$ & $20 / 1000$ & - & - \\
\hline 23 & 60 & $M$ & $\mathrm{R}$ & - & 3 & $20 / 400$ & $20 / 1200$ & - & - \\
\hline 24 & 80 & $M$ & $\mathrm{R}$ & - & 1 & $20 / 1200$ & LP & + & - \\
\hline 25 & 57 & $M$ & $\mathrm{~L}$ & HTN & 1 & $20 / 240$ & $20 / 100$ & - & - \\
\hline 26 & 50 & $\mathrm{~F}$ & $\mathrm{R}$ & $\mathrm{HCH}$ & 1 & $20 / 1200$ & $\mathrm{HM}$ & + & - \\
\hline 27 & 36 & $M$ & $\mathrm{~L}$ & HTN & 2 & $20 / 240$ & $20 / 600$ & - & - \\
\hline 28 & 70 & $M$ & $\mathrm{~L}$ & $\mathrm{HCH}$, glaucoma & 1 & $20 / 400$ & $20 / 1200$ & - & - \\
\hline
\end{tabular}


Table 2 Multinomial logistic regression analysis; significance levels of the models and each covariate along with $r^{2}$ are presented

\begin{tabular}{|c|c|c|c|c|c|}
\hline & \multirow[b]{2}{*}{$r^{2}$} & \multicolumn{4}{|c|}{ Significance values } \\
\hline & & Model & $\begin{array}{l}\text { Study } \\
\text { group }\end{array}$ & $\begin{array}{l}\text { Presentation } \\
\text { VA }\end{array}$ & $\begin{array}{l}\text { Presentation } \\
\text { time }\end{array}$ \\
\hline Neovascularisation & 0.291 & 0.022 & 0.006 & 0.150 & 0.650 \\
\hline $\begin{array}{l}\text { Month } 8 \text { post-event } \\
\text { VA }\end{array}$ & t 0.077 & 0.525 & 0.140 & 0.409 & 0.491 \\
\hline VA improvement & 0.296 & 0.02 & 0.007 & 0.933 & 0.121 \\
\hline
\end{tabular}

cases of neovascular glaucoma, two of disc neovasularisation, and one of iris neovascularisation occurred.

The two groups were not significantly different in the distribution of age, sex, hypertension, diabetes mellitus, and glaucoma ( $\mathrm{p}$ values were $0.584,0.433,1.0,0.357$, and 1.0, respectively). However, mean presentation time for the surgical group was nine weeks later than that of the controls and mean $\log$ MAR of presentation VA were 2.5 and 1.5 for surgical and control groups, respectively $(p<0.001)$. Hypercholesterolemia was significantly more common in the surgical groups $(60 \% \vee 17 \%, \mathrm{p}=0.035)$.

In multivariate analysis, surgery was shown to be the sole significant predictor of the visual improvement and the prevention of neovascularisation (table 2).

\section{DISCUSSION}

The current treatment modalities for retinal vein occlusion, such as laser or surgical induction of chorioretinal anastomosis, administering tissue plasminogen activators, transvitreal cannulation of the retinal vein, transecting the posterior scleral ring, and radial neurotomy, aim at restoring venous flow by bypassing the occlusion. These are in opposition to the classic approach in the management of retinal vein occlusions in which the consequences of the retinal vein occlusion are treated, such as macular oedema and neovascularisation. ${ }^{16-19}$

Histological studies have shown that the central retinal vein may become permanently narrowed by the thickened walls after an intraluminal thrombus has recanalised ${ }^{20}$ and perhaps alternative pathways for venous blood to exit the impeded retinal circulation should be considered. Such pathways may occur naturally in CRVO with the so-called optociliary anastomosis. ${ }^{9}$ It was thought that performing a retinal vein bypass in eyes with an ischaemic vein occlusion was not likely to lead to either reperfusion of the areas of retinal capillary dropout or improved VA. ${ }^{21}$ However, it has been hypothesised that if the parafoveal and perifoveal areas remain non-ischaemic in an eye with an otherwise largely ischaemic CRVO, there may be some visual benefit from improved venous outflow and lessened macular oedema. In addition, the iatrogenic shunt induction may reduce the likelihood of the development of neovascularisation. ${ }^{12}$

Our study showed that surgical shunt induction can result in VA improvement (80\% of our cases had some improvement). Peyman et al also reported 60\% VA improvement in a similar cohort of ischaemic CRVO cases. ${ }^{12}$

Additionally, the shunts seemed to prevent the development of neovascularisations in the operated cases. One may argue that the patients in the surgical category presented when the risk of developing neovascularisation had been largely eliminated. In fact the risk of the development of neovascularisation persists for at least eight months after retinal vein occlusion. ${ }^{4}$ However, we believe that the argument is relevant but cannot fully explain such a difference in the magnitude of the occurrence of neovascularisation between the two groups and, as stated, occurrence of neovascularisation was best predicted by the study group (table 2).

Central retinal vein occlusion occurs at the level of the lamina cribrosa. The bifurcation of the superior and inferior central retinal veins occurs anterior to the lamina cribrosa; so the entire retina could be drained with a single inferior anastomosis. ${ }^{22}$ Although our surgical success (defined as patent/induced shunts) was $47 \%$ and less than that of Peyman's report $(62.5 \%),{ }^{12}$ the clinical success (defined as uneventful postoperative course and development of at least one inferiorly placed active shunt) was $90 \%$ (Koizumi et al reported a clinical success of $70 \%$ for surgical shunt induction in a group of intermediate CRVO subjects ${ }^{10}$ ).

It seemed that those who referred to us early in their course had less of a desire for operation (mean presentation time difference of nine weeks for the surgical $v$ control groups; $\mathrm{p}<0.0004)$. Conforming to the expected natural course of CRVO in the early post-event months, those who presented late had worse vision. The later the patients presented, the worse their vision (in our study the Pearson coefficient for the presentation time and presentation VA was $0.433, \mathrm{p}=0.021)$. This might have made these cases more receptive for the surgical choice. As stated, in multivariate analysis, surgery was shown to be the sole significant predictor of the visual improvement (table 2).

In statistical terms, some of the improvements and deteriorations of VA-respectively, in the surgical cases and the controls-could be attributed to the regression-towardsmean phenomenon and this may invalidate the inference of the effect of the surgery. This phenomenon may explain part or all of the observation on the control cases-that is, the VA deterioration. But in the case of VA improvement in surgical cases, studies on the natural course of ischaemic CRVO have shown that only $10 \%$ of these cases gain or maintain a VA of $20 / 400$ or better ${ }^{23}$ (in our study $60 \%$ of the surgical cases achieved a VA of $20 / 400$ or better).

Three $(30 \%)$ of our patients needed further surgery-for retinal detachment, vitreous cavity haemorrhage, and cataract. Three of the five patients in Peyman's study needed further surgery for retinal detachment, vitreous cavity haemorrhage, and cataract. ${ }^{12}$ One of the patients in Koizumi et al's study needed further operation for recurrent fibrous proliferation and vitreous cavity haemorrhage. ${ }^{10}$ Hence, the safety profile seems quite acceptable compared with other modalities (see below).

The possibility of selective creation of retinal-choroidal vein anastomosis by high energy laser photocoagulation has been demonstrated, but this is difficult to achieve in patients with significant media opacities, with a reported clinical success rate of $33-54 \% .^{924}{ }^{25}$ A grossly swollen retina may prevent target tissue disruption and there are certain complications such as subretinal and vitreous haemorrhages, rubeosis, neovascular membrane formation, and preretinal and subretinal fibrosis in eyes with intact posterior cortical vitreous; another complication noted was the occlusion of the distal portion of the venous tributary. ${ }^{9}$ This can induce ischaemia to a level that makes neovascularisation very likely. McAllister et al reported a complication rate of $29 \%$ for neovascular membrane formation and avascular fibrous proliferation. ${ }^{24}$ Theoretically, reperfusion of the remaining retinal capillaries resulting from surgical shunt induction and controlled creation of the shunts must lessen the risk of such complications-in our study none of these complications was observed in the follow ups.

Anticoagulants, both parenterally and intravitreally, may ease the passage of blood past the site of obstruction or dissolve the thrombus. ${ }^{26}$ Hattenbach et al reported VA improvement in $44 \%$ of their ischaemic cases, ${ }^{27}$ but as thrombus 
organisation and endothelial cell proliferation seem to occur early ${ }^{6}$ the potential benefit should be limited. Additionally, parenteral injection could be associated with systemic bleeding complications and even death. ${ }^{26}{ }^{28}$ On the other hand, intravitreal injection could just be considered in acute management of non-ischaemic CRVO (presentation earlier than seven days). ${ }^{6}$ Transvitreal cannulation of retinal veins has been reported in animal models and is currently under investigation..$^{29} 30$

Radial optic neurotomy has been studied recently for the management of ischaemic and/or severe CRVO cases. Preliminary data showed that it could result in VA improvement or stabilisation in the majority of cases. Moreover, the procedure has been reported to induce optociliary shunt development. ${ }^{31-34}$ The clinical efficacy of the procedure has to be evaluated in a comparative manner. ${ }^{7}$

Following the vascular insult in ischaemic CRVO-during the ensuing months-the inner retina undergoes progressive degenerative changes and the architecture of fovea is disrupted. In our study, the patients operated on earlier gained a better final VA. This finding failed to achieve statistical significance $(p=0.134)$; however, we attributed that to the relatively small sample size of the study. So it could be well advised that surgical intervention-if chosenbe applied at the earliest time before irreversible changes develop in the macula.

It seems that the very development of shunt, regardless of the method of induction (whether laser induced (Argon ${ }^{91}$ or Erbium:YAG ${ }^{13}$ ) or surgically induced, ${ }^{10}{ }^{12}$ ) is associated with VA improvement. It is argued that vitrectomy itself may also contribute to VA improvement and prevention of complications. ${ }^{35}$ Some intrinsic metabolic agents seem to be responsible for ischaemia and the development of cystoid macular oedema and, in eyes with vitreous macular attachment, the oedema persists because the metabolic agents remains in contact with macula. Complete posterior vitreous detachment seems to protect against retinal or optic disc neovascularisation. ${ }^{36}{ }^{37}$ Centripetal traction transmitted to the Muller cells by vitreous fibres inserted into the macula in an eye with intact vitreous macula interface is another explanatory mechanism. So, vitrectomy may eliminate the retina access to metabolic agents present in the vitreous as well as the mechanical traction on the macula; this way it might result in better perfusion and prevent retinal and optic disc neovascularisation. ${ }^{13}$ In our study, none of the surgical patients developed anterior or posterior segment neovascularisation.

Similar to the previous reports, ${ }^{12} 7$ we performed peripheral retinal photocoagulation for our patients. It could be argued that photocoagulation actually prevented neovascularisation. Vitrectomy generally may increase the likelihood of anterior segment neovascularisation because it facilitates the access of angiogenic factors into the anterior chamber (although as stated it may decrease the likelihood of posterior neovascularisation); in order to counteract this untoward effect, ${ }^{7}$ mild peripheral retinal photocoagulation was applied. Our total dose of photocoagulation was far less than the dosage applied in the Central Vein Occlusion Study and the study did not recommend prophylactic retinal photocoagulation as it could not eliminate the risk of neovascularisation (despite prophylactic photocoagulation, some $20 \%$ developed neovascularisation; although it was less than the $35 \%$ occurrence in the control group, the difference was not statistically significant). ${ }^{18}$ Although the prevention of neovascularisation may be in part or wholly explained by photocoagulation, this does not seem to explain VA improvement.

In conclusion, surgically induced chorioretinal venous anastomosis may be considered as a viable therapeutic option for the management of ischaemic CRVOs. Future studies should aim at evaluation of the selective role of vitrectomy, posterior vitreous detachment induction, photocoagulation, and the shunt formation itself. Because of the nonrandomised nature of the study and small size of the sample, stricter designs such as randomised controlled trials are needed to control the effects of potential confounders to better estimate the true clinical efficacy and safety. Furthermore, the role of this modality should be placed in the context of other emerging approaches in the management of retinal vein occlusion, such as radial optic neurotomy, which has shown preliminary success.

\section{ACKNOWLEDGEMENTS}

The manuscript is based on the residency thesis of Dr R Roohipoor. Authors would like to express their gratitude to Dr M Hoseinian for his support and Dr S Moghimi for case referrals.

\section{Authors' affiliations}

A Mirshahi, R Roohipoor, A Lashay, S F Mohammadi, M R Mansouri, Eye Research Center, Farabi Eye Hospital, Tehran University of Medical Sciences, Tehran, Iran

\section{REFERENCES}

1 Giardella AP, Clarkson JG, Guyer DR, et al. Retina-Vitreous-Macula. In: Guyer DR, Yannuzzi LA, Chang S, et al, eds. Central retinal vein occlusion: a textbook. Philadelphia: Saunders, 1999;v. 1:286-307.

2 Klein R, Klein BE, Moss SE, et al. The epidemiology of retinal vein occlusion: the Beaver Dam Eye Study. Trans Am Ophthalmol 2000;98:133-43.

3 Mitchell P, Smith W, Chang A. Prevalence and associations of retinal vein occlusion in Australia: The Blue Mountains Eye Study. Arch Ophthalmol 1996:114:1243-7.

4 Hayreh SS. Central Retinal Vein Occlusion. http://webeye.ophth.viowa.edu/ dept/crvo/ follow links for the pages (accessed 13 December 2003).

5 Zegarra H, Gutman FA, Conforto J. The natural course of central retinal vein occlusion. Ophthalmology 1979;86:1931-42.

6 Fekrat S, Finkelstein D. Current concepts in the management of central retinal vein occlusion. Curr Opin Ophthalmol 1997;8:50-4.

7 Williamson TH, Poon W, Whitefield L, et al. A pilot study of pars plana vitrectomy, intraocular gas, and radial neurotomy in ischaemic central retinal vein occlusion. Br J Ophthalmol 2003;87:1126-9.

8 Verhoeff FH. Successful diathermy treatment in a case of recurring retinal hemorrhage and retinitis proliferans. Arch Ophthalmol 1948;40:239-44.

9 Mc Allister IL, Constable IJ. Laser-Induced chorioretinal venous anastomosis for treatment of nonischemic retinal vein occlusion. Arch Ophthalmol 1995; 113:456-62.

10 Koizumi K, Nishiura M, Yamamoto T, et al. Intentional complete interruption of a retinal vein after vitrectomy might improve the rate of successful chorioretinal venous anastomosis formation in central retinal vein occlusion. Graefes Arch Clin Exp Ophthalmol 2002;240:787-94.

11 Fekrat S, de Jaun E. Chorioretinal venouse anastomosis for central retinal vein occlusion:transevitreal veni-puncture. Ophthalmolmic Surg Lasers 1999;30:52-9.

12 Peyman GA, Kishore K, Conway MD. Surgical chorioretinal venous anastomosis for ischemic central retinal vein occlusion. Ophthalmic Surg Lasers 1999;30:605-14.

13 Quiroz-Mercado H, Sanchez Buenfil E, Guerrero-Naranjo JL, et al. Successful erbium: YAG laser-induced chorioretinal venous anastomosis for the management of ischemic central retinal vein occlusion. A report of two cases. Graefes Arch Clin Exp Ophthalmol 2001;239:872-5.

14 Browning DJ. Fundus photographic, fluorescein angiographic, and indocyanine green angiographic signs in successful laser chorioretinal venous anastomosis for central retinal vein occlusion. Ophthalmology 1999; 106:2261-8.

15 Holladay J. Proper method for calculating visual acuity. Refractive Surg 1997; 13:388-91

16 Branch vein occlusion study group. Argon laser photocoagulation for macular edema in barnch vein occlusion. Am J Ophthalmol 1984;98:271-82.

17 Branch vein occlusion study group. Argon laser scatter photocoagulation for prevention of neovascularization and vitreous hemorrhage in branch vein occlusion: a randomized clinical trial. Arch Ophthalmol 1986;104:34-41.

18 Central vein occlusion study group. Evaluation of grid pattern photocoagulation for macular edema in central vein occlusion: the central vein occlusion study group M report. Ophthalmology 1995;102:1425-33

19 Central vein occlusion study group. A randomized clinical trial of early panretinal photocoagulation for ischemic central vein occlusion: the central vein occlusion study group $\mathrm{N}$ report. Ophthalmology 1995;102:1434-44.

20 Green WR, Chan CC, Hutchins GM, et al. Central retinal vein occlusion prospective histological study of 29 eyes in 28 cases. Trans Am Ophthalmol $1981 ; 89: 371-472$.

21 Fekrat S, Goldberg MF, Finkelstein D. Laser induced chorioretinal venous anastomosis for non-ischemic central or branch retinal vein occlusion. Arch Ophthalmol 1998;116:43-52.

22 Reimbold SM. latrogenic chorioretinal venous anastomosis in the treatment of central retinal vein occlusion. Clin Eye Vis Care 1996;8:141-7. 
23 Zegarra H, Gutman FA, Conforto J, et al. The natural course of central retinal vein occlusion. Ophthalmology 1997;86:1931-42.

24 McAllister IL, Douglas JP, Constable IJ, et al. Laser-induced chorioretinal venous anastomosis for nonischemic central retinal vein occlusion: evaluation of the complications and their risk factors. Am J Ophthalmol 1998:126:219-29.

25 Aktan SG, Subasi M, Akbatur H. Problems of chorioretinal venous anastomosis by laser for treatment of nonischemic central retinal vein occlusion. Ophthalmologica 1998;212:389-93.

26 Vannas S, Raitta C. Anticoagulation treatment of retinal venous occlusion. Am J Ophthalmol 1966;62:874-81

27 Hattenbach LO, Wellermann G, Steinkamp GW, et al. Visual outcome after treatment with low-dose recombinant tissue plasminogen activator or hemodilution in ischemic central retinal vein occlusion. Ophthalmologica 1999;213:360-6

28 Radnot M, Follmann P. Rheomacrodex (dextran) in treatment of the occlusion of the central retinal vein. Ann Ophthalmol 1969;1:58-64.

29 Allf BE, de Juan E Jr. In vivo cannulation of retinal vessels. Graefes Arch Clin Exp Ophthalmol 1987;225:221-5.
30 Suzuki $Y$, Matsuhashi $\mathrm{H}$, Nakazawa $M$. In vivo retinal vascular cannulation in rabbits. Graefes Arch Clin Exp Ophthalmol 2003;241:585-8.

31 Opremcak EM, Bruce RA, Lomeo MD, et al. Radial optic neurotomy for central retinal vein occlusion: a retrospective pilot study of 11 consecutive cases. Retina 2001;21:408-15.

32 Garciia-Arumii J, Boixadera A, Martinez-Castillo V, et al. Chorioretina anastomosis after radial optic neurotomy for central retinal vein occlusion. Arch Ophthalmol 2003;121:1385-91.

33 Le Rovic JF, Becquet F, Zanlonghi $X$, et al. Radial optic neurotomy for severe central retinal vein occlusion: preliminary results. J Fr Ophtalmol 2003;26:577-85

34 Friedman SM. Optociliary venous anastomosis after radial optic neurotomy for central retinal vein occlusion. Ophthalmic Surg Lasers Imaging 2003:34:315-17.

35 Stefansson E, Novack RL, Hatchell DL. Vitrectomy prevents retinal hypoxia in branch retinal vein occlusion. Invest Ophthalmol Vis Sci 1990;31:284-9.

36 Fine BS, Brucker AJ. Macular edema and cystoid macular edema. AM J Ophtalmol 1981;92:466-81.

37 Yanoff M, Fine BS, Brucker AJ, et al. Pathology of human cystoid macular edema. Surv Ophthalmol 1984;28:505-11.

\section{Video reports}

To view the video reports in full visit our website www.bjophthalmol.com and click on the link to the video reports.

- Bilateral Abducens Neuromyotoniah. L H Ospina, N Aui-aree, D P Anderson

- Light to dark physiological variation in irido-trabecular angle width. GM Gazzard, P J Foster, D S Friedman, P T Khaw, S K L Seah

Video Suite: Triamcinolone-assisted vitrectomy

- Triamcinolone-assisted removal of the posterior hyaloid to repair retinal detachment due to macular hole in high myopia. A Ueno, H Enaida, Y Hata, T Nakamura, T Hisatomi, K Fujisawa, $T$ Kubota, $T$ Sakamoto, $T$ Ishibashi

- Triamcinolone acetonide-assisted Epiretinal Membrane Peeling. S D M Chen, C K Patel

- A suture technique to manage a case of severe early flap displacement after laser in situ keratomileusis. L Spadea, P Pantaleoni, G Bianco

- Reconstruction of the Ocular Surface in LOGIC Syndrome. E Moore, V Kumar, J R Ainsworth, S Shah

- Laser Photocoagulation for Posterior Segment Intraocular Parasites. T Prabriputaloong, S Asawaphureekorn

- Feeder Vessel Treatment with High Speed ICG Angiography. D Stanescu-Segall, G Coscas, F Coscas, G Soubrane

- Endoscopy to aid anterior segment surgery. J E Moore, A Sharm

- Penetrating ocular injury due to a fish hook: Surgical removal. SD M Chen, D Chiv, CK Patel

- Retinal Ganglion Cell Axon Response to Guidance Molecules. SF Oster and DW Sretavan

- Marin-Amat Syndrome. A Jogiya, C Sandy

- Excision of subcutaneous Dirofilariasis of the eyelid. D Mallick, T P lityerah

- Thixotropy: a novel explanation for the cause of lagophthalmos after peripheral facial nerve palsy. M Aramideh, J H T M Koelman, P P Devriese, F VanderWerf, J D Speelman

- Surgical revision of leaking filtering blebs with an autologous conjunctival graft. $K$ Taherian, A Azuara-Blanco

- Dipetalonema Reconditum in the human eye. T Huynh, J Thean, R Maini 